\title{
Entre lugares e imagens: 0 uso de dispositivos de realidade virtual e a percepção espacial
}

\section{Eduardo Zilles Borba}

\begin{abstract}
Resumo
0 trabalho realiza uma abordagem sociotécnica para investigar as relações do usuário com dispositivos de Realidade Virtual, em específico o modelo HeadMounted Display (HMD). Parte-se do princípio de que as relações e intersecções da agência usuárioambiente virtual são governadas pelos espaços imaginado, enunciado e material. Conduziram-se experiências empíricas, nas quais oito participantes exploraram ambientes imersivos utilizando o HMD e, após as explorações, participaram de entrevistas semiestruturadas. Em suma, a percepção de espaço imaginado foi relevante para usuários inexperientes, enquanto o espaço enunciado foi relevante para experientes e, por fim, o espaço material conectou as percepções espaciais de ambos.
\end{abstract}

\section{Palavras-Chave}

Realidade virtual. Dispositivos. Percepção espacial. Materialidades. Tecnologias da comunicação.

\section{Eduardo Zilles Borba | ezb@|si.usp.br}

Doutor em Ciências da Informação pela Universidade Fernando Pessoa, UFP - Portugal. Pesquisador do CITI na Universidade de São Paulo, USP - Brasil. Pós-Doutorando em Eletrônica na USP. Professor das Faculdades Integradas de Taquara - FACCAT, Brasil.

\section{Ponto de partida}

Esta pesquisa investiga as relações e intersecções entre os usuários, os dispositivos de Realidade Virtual (RV) e os ambientes virtuais, levando em conta as materialidades da experiência e das agências existentes nessa triangulação de processos comunicacionais. Parte-se do princípio de que as ações dos atores (usuários, dispositivos de RV, ambientes virtuais) são mutuamente conectadas. Sendo assim, questiona-se: como a percepção e a experiência espacial são afetadas pelos dispositivos de RV, especificamente os $H M D s$, na agência entre usuários e ambientes virtuais?

\section{Realidade virtual em números, índices e mercados}

Nos meses iniciais de 2014, por meio do seu fundador, Mark Zuckerberg, o Facebook anunciava a aquisição da startup criadora do dispositivo de RV Oculus Rift' ${ }^{1}$ Entre ações da empresa e transições financeiras, o valor da compra chegava aos U\$ 2 bilhões. Por ter uma base de mais de um 
milhão de usuários ativos em seu site de redes sociais ${ }^{2}$ e, também, por ostentar a reputação de ser uma das principais empresas de tecnologia da atualidade, 0 investimento do Facebook chamou a atenção. Quais seriam os planos da empresa para essa tecnologia? A resposta provável: num futuro próximo, a rede social da empresa proporcionará encontros de negócios e/ou familiares em mundos virtuais ${ }^{3}$. E, de fato, isso parece consolidar-se, cada vez mais, com 0 lançamento do Facebook Spaces ${ }^{4}$, uma versão em $\mathrm{RV}$ para a rede social on-line.

No momento, os planos do Facebook não são relevantes para esta pesquisa. Porém, é importante estar-se atento às movimentações desse gigante do setor tecnológico. Afinal de contas, mesmo que a RV seja uma tecnologia conhecida há décadas por pesquisadores, foi após essa significativa aquisição que muitas pessoas (e veículos de mídia) passaram a se interessar pelos dispositivos de RV (GRAFT, 2014).

Há décadas que os laboratórios e centros de pesquisa utilizam-na para realizar experiências com efeito de real. Agora, devido aos recentes avanços da computação gráfica $\mathrm{e}$ dos equipamentos tecnológicos, este modelo de interface tem se destacado para além do seio universitário, despertando o interesse do meio corporativo. (ZILLES BORBA et al., 2015, p. 356-357).

Experimentos artísticos e/ou simulações de guerra são alguns dos exemplos de utilização da RV desde a década de 1970 (KIRNER; TORI, 2004). Entretanto, a vasta potencialidade de uso dessa tecnologia abrange inúmeros mercados: militar, artes, medicina, turismo, educação, entretenimento etc. (ZILLES BORBA; PAZ, 2016). A Universidade de São Paulo, por exemplo, utiliza esse recurso tecnológico desde 2014 para proporcionar experiências de realidade virtual aos estudantes de arqueologia, numa forma não destrutiva de "teletransportar" centenas de pessoas para um sítio arqueológico no interior do país (ZILLES BORBA et al. 2016).

Os números no mercado da RV demonstram um cenário de possibilidades. Em 2016 foram investidos U\$ 2,8 bilhões e, até 2020, há estimativas de que esse número alcance U\$ 30 bilhões ${ }^{5}$. Num reflexo natural às projeções, especulações e promessas de ascensão deste

Disponível em: https://techcrunch.com/2014/07/21/facebooks-acquisition-of-oculus-closes-now-official/. Acesso em 14 mar. 2017.

Disponível em: http://tecnologia.uol.com.br/noticias/afp/2014/02/03/facebook-em-numeros.htm. Acesso em 14 mar. 2017.

3 Disponível em: http://www.vanityfair.com/news/2015/09/oculus-rift-mark-zuckerberg-cover-story-palmer-luckey. Acesso em 14 mar. 2017.

https://www.facebook.com/spaces

Conforme dados da empresa de pesquisas SuperData Research. Disponível em: https://www.superdataresearch.com/blog/ virtual-reality-market-brief/. Acesso em 14 mar. 2017. 
mercado, diversas empresas passaram a desenvolver hardwares para explorar a RV: HTC Vive ${ }^{6}$, Playstation VR ${ }^{7}$, Samsung Gear $\mathrm{VR}^{8}$, Google Cardboard ${ }^{9}$, etc. Outros dados dão conta de que, até 2020, a maior fatia dos investimentos deverá ser destinada à indústria dos jogos eletrônicos (Figura 1).

Figura 1: projeção de mercados responsáveis pelo investimento em RV até 2020

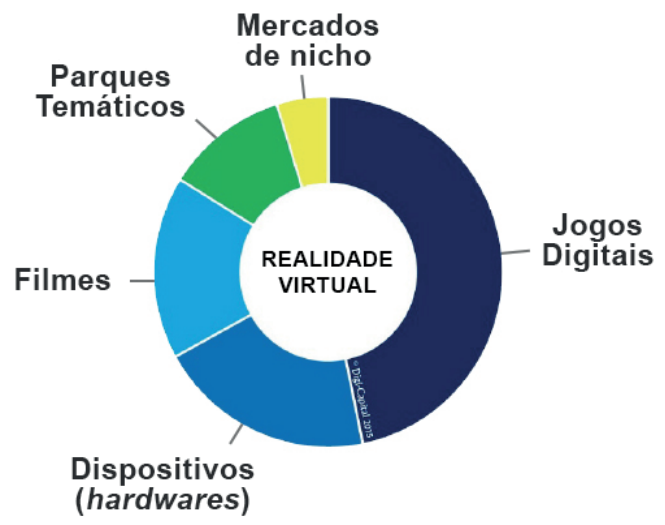

Fonte: adaptado de Digi-Capital Research (2015) ${ }^{10}$.

\section{0 dispositivo HMD}

A RV deve ser entendida como um modelo de interface avançada entre usuário e computador, segundo Kirner e Tori (2004), na qual o sujeito pode visualizar e manipular objetos virtuais, além de interagir com eles, numa simulação com elevadas semelhanças audiovisuais e funcionais/hápticas ao mundo real (formas, escalas, proporções, perspectivas, texturas, gestos, movimento, etc.).

Para Burdea (2003), as ações em RV são sustentadas por três pilares: 0 realismo gráfico e sonoro, a interatividade natural ao humano e 0 envolvimento com 0 enredo da cena virtual. Quanto mais esses três fatores se aproximarem das aparências e/ou comportamentos do mundo real, maior será o grau de imersão do usuário na experiência virtual (ZILLES BORBA, 2016).

$\mathrm{Na}$ atualidade, existem dois tipos de equipamentos de RV: os Head-Mounted Displays (HMDs) e as Cave Automatic Virtual Environments (CAVEs). Segundo Domingues (2004), as CAVES, ou cavernas, são salas cúbicas que recebem imagens geradas por computadores através de projeções em suas paredes, teto e chão translúcidos, criando um elevado grau de envolvimento da pessoa com o espaço virtual. Por sua vez, os HMDs são uma espécie de capacete e óculos que o usuário utiliza na cabeça. Eles dispõem de uma tela afixada na altura dos olhos, que permite acesso em $360^{\circ}$ ao ambiente virtual, pois o equipamento acompanha as movimentações da cabeça do indivíduo (Figura 2).

Disponível em: https://www.vive.com/us/product/vive-virtual-reality-system/. Acesso em 14 mar. 2017.

Disponível em: https://www.playstation.com/pt-br/explore/playstation-vr/. Acesso em 14 mar. 2017.

Disponível em: http://www.samsung.com/br/wearables/gear-vr-2017/. Acesso em 14 mar. 2017.

Disponível em: https://vr.google.com/cardboard/. Acesso em 14 mar. 2017.

10 Disponível em: http://www.digi-capital.com/news/2015/04/augmentedvirtual-reality-to-hit-150-billion-disrupting-mobileby-2020/\#.V5EkoaKDfE9. Acesso em 14 mar. 2017. 
Figura 2: modelos de dispositivos RV (HMD na esquerda e CAVE na direita)

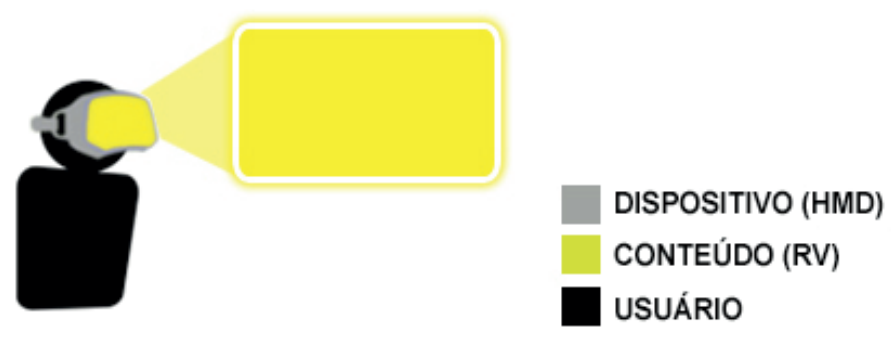

Apesar de a demanda do público consumidor ainda não estar clara sobre 0 tipo de dispositivo de RV a ser utilizado em atividades rotineiras, neste estudo consideramos apenas os modelos em HMD. Essa escolha justifica-se na própria movimentação dos mercados e das pesquisas em tecnologia e comunicação apresentadas no capítulo anterior. Pressupõem-se que, à medida que esses dispositivos se tornaram mais acessíveis às massas - em relação a preço, distribuição e facilidade de uso -, tornar-se-á imperativo investigar as experiências midiáticas resultantes destas relações e intersecções entre pessoas, dispositivos e ambientes virtuais.

\section{Um mergulho no ambiente comunicacional: interface com quase-coisas}

Independentemente de se utilizar uma CAVE ou um HMD, ambas as interfaces com a RV proporcionam o mergulho do usuário no contexto digital. Slater e Wilbur (1997) lançaram um conceito interessante, na década de 1990, ao sugerir que esse mergulho pode ser estimulado de duas maneiras: por experiências objetivas (imersão) ou por experiências subjetivas (presença). Nesse sentido, a imersão seria 0 resultado de uma experiência objetiva, na qual os dispositivos estimulam o corpo da pessoa a crer que está dentro do cenário virtual (ver, ouvir, tocar, etc.); enquanto a sensação de presença seria 0 resultado de uma experiência subjetiva, na qual fatores mentais e psicológicos seriam responsáveis por estimularem o imaginário da pessoa a crer que ela participa de um contexto virtual (afeto, gostos, transferência de atenção, storytelling, etc.).

Para Kerckhove (1995), quanto mais discreta for a participação dos dispositivos mediadores das experiências entre usuário e ambiente virtual, maior será sua percepção de habitar o cenário artificial. Em suas palavras, as pessoas podem fazer uma plástica da psique ao assumir outros 
corpos, outras personalidades e experiências em simulações eletrônicas da realidade, numa espécie de materialização do corpo no espaço virtual ou, ao contrário, numa desmaterialização do corpo no espaço real. Conforme Negroponte (1995), as possibilidades estéticas e funcionais dos ambientes de RV indicariam uma oportunidade para que a sociedade se tornasse ainda mais digital. Isto é, se o modus operandi das ações humanas no mundo real forem realmente transpostas para o mundo virtual, as universidades, os negócios e as relações teriam um cenário fértil para atuar no modo de telepresença, como uma extensão eletrônica da vida - a materialidade do bit.

Ainda, se unirmos o pensamento de Kerckhove (1995) com as ideias de Negroponte (1995), podemos refletir sobre uma construção de materialidades artificiais para a sociedade da informação sugerida por Castells (1999). Ou seja, mais do que atuar via fluxos comunicacionais em interfaces icônicas e metafóricas da realidade (botões, menus, ícones, pastas, janelas, etc.), as pessoas atuariam via fluxos comunicacionais em interfaces que fazem analogia com o real, numa espécie de mimética das estéticas e funcionalidades da realidade (pegar, caminhar, tocar, manipular, falar etc.).

Sobre materialidades e estéticas, Picon (2004) diz que a RV suporta experiências com quasecoisas, pois realizamos ações com quase-objetos e quase-espaços. Nesta perspectiva, Lévy
(1996) trouxe importantes contributos para as reflexões acerca da materialidade, da estética e da sensorialidade. Partindo dos princípios epistemológicos sobre realidade e virtualidade, 0 pensador francês buscou o pensamento de Platão sobre o Mundo das Ideias e a Teoria da Formas, para explicar que 0 conceito de virtual remete à virtude e à potência, num espaço em que as ideias, os objetos e as ações são potencializados pelas propriedades binárias do meio digital. Nesse caso também citamos Luhman (2005), ao sugerir que a construção de realidade também é afetada pelos meios de comunicação. Ora, mesmo que não seja imposto, 0 autor indica que as mídias influenciam nossa noção de realidade - opinião pública, esfera social etc. - criando uma duplicação da realidade.

\section{Agência, affordances e tecnointerações}

Para compreender como a percepção espacial, a agência e as materialidades relacionam-se com dispositivos e ambientes de RV durante as práticas do usuário, este trabalho apresenta 0 conceito de affordances. A partir de uma perspectiva sociotécnica, procura-se compreender como a tecnologia (o ambiente) e a técnica (o dispositivo) produzem e reproduzem contextos sociais, culturais e econômicos (FRAGOSO et al., 2012). Já dizia Benjamin (1983) que é impossível analisar o comportamento da sociedade sem considerar a influência de fatores técnicos intrínsecos ao uso dos dispositivos; já para McLuhan (1964), o comportamento da sociedade é mais influenciado pelo uso das mídias do que pelo conteúdo delas. 
É nesses pontos que as affordances oferecem matrizes teóricas para 0 entendimento de fenômenos sociais em ambientes tecnológicos. 0 termo, de difícil tradução para o português, foi cunhado na psicologia ambiental de Gibson (1977, apud FRAGOSO et al., 2012), quando indicou a existência das affordances na intersecção da relação entre ambientes e animais, entre 0 que é objetivo, tangível e quantificável e o que é subjetivo; por exemplo, como os animais comportam-se e percebem os seus arredores. Traduzindo essa ideia para a relação entre humanos e tecnologias digitais, Fragoso et al. (2012) argumentam que as affordances levam à compreensão de que as pessoas não apenas utilizam tecnologias como seus projetistas pretendem, mas as transformam, subvertem e adaptam, assim como as tecnologias modificam, subvertem e adaptam práticas dos usuários. Neste sentido, entende-se que as affordances implicam tanto o entendimento do que os dispositivos de RV possibilitam ao usuário como, também, as possibilidades de apropriação de uso que ele faz destas extensões tecnológicas. Esse pensamento assemelha-se ao da teoria da midiatização, desenvolvido por Ferreira (2007), ao definir que as relações e intersecções entre dispositivos, processos sociais e processos comunicacionais influenciam-se mutuamente (Figura 3).

À luz das ideias de Gibson (1977), Nagy; Neff (2015) elaboraram o conceito de affordances imaginadas ${ }^{11}$. Considerando ambientes mediados, sua proposta conecta a ação humana com as "coisas" tecnológicas, num enquadramento teórico

Figura 3: relações e interseções entre dispositivos, processos sociais e processos comunicacionais

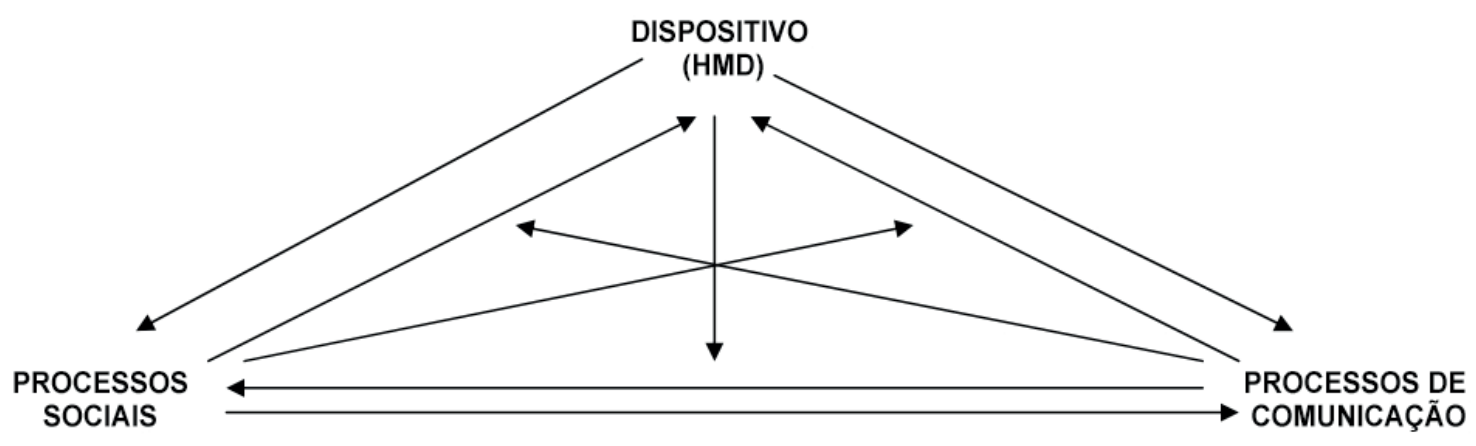

Fonte: adaptado de Ferreira (2007) 
que relaciona percepção e materialidade. Nessas condições, os autores apontam que a pesquisa pode refletir para as qualidades materiais que afetam as experiências dos usuários. Esta proposta dá conta do que os usuários e projetistas imaginam para as tecnologias, desconstruindo regras e protocolos enraizados em objetos técnicos. Isto é, os dispositivos de RV prometem "transportar" as pessoas para outros espaços, mas de que forma os usuários querem ser transportados e até onde a tecnologia possibilita essas experiências? Para Sodré (2001), isso tudo implica a formulação de uma nova tecnologia perceptiva mental, um novo tipo de relacionamento do indivíduo com as referências concretas e com a verdade. Ou melhor, implica um relacionamento do indivíduo com 0 que ele acredita ser verdade (sua percepção de realidade). Este processo de apropriação das tecnologias interativas é chamado por ele de tecnointerações.

Estamos assistindo a uma multiplicação, uma disseminação das tecnointerações na vida social [...] aí está um ponto de poder que dá a especificidade do objeto da comunicação, exigindo uma nova antropologia ético-política da comunicação ou uma nova teoria da comunicação. Um desafio de redescrever o homem diante das novas tecnologias: esta é a questão da antropologia ético-política da comunicação. Redescrever como o homem, 0 indivíduo, o sujeito humano se situa diante de uma sociedade que é por inteira, mesmo nas suas zonas de pobreza, atravessada por tecnologias. Depois, levar em conta as transformações da consciência, dos jovens que agora estão brincando o tempo inteiro com computador, com videojogos, sob o influxo de uma ordem cultural que é de ordem simulativa. (SODRÉ, 2001, p.2-3)
Nas tecnointerações entre usuário, dispositivo e ambiente virtual, também há de se considerar as relações materiais. Afinal, um HMD na cabeça afeta como 0 usuário identifica, interpreta e significa a sua experiência espacial. 0 que é material, aponta Gumbrecht (2004), pode não gerar uma interpretação hermenêutica, entretanto produz sentido e interfere na experiência espacial mediada pelo dispositivo. Gumbrecht adiciona: "qualquer forma de comunicação, com seus elementos materiais, 'tocará' os corpos das pessoas que estão em comunicação de modos específicos e variados" (GUMBRECHT, 2004, p. 39). Essas ideias sugerem que não somente 0 HMD acoplado na cabeça do usuário interfira na experiência, mas também o local físico onde a pessoa acessa o mundo virtual, se é na sala ou quarto de uma casa, se tem outras pessoas circulando pelo local e quais outros hardwares e softwares integram a agência entre usuário e ambiente virtual. Neste artigo, por jogador e game leia-se usuário e ambiente virtual. Esse processo relacional se estabelece em instâncias heterogêneas e é central na compreensão da experiência e na percepção espacial do sujeito em dispositivos de RV.

[...] processo contínuo de negociação entre 0 jogador e o jogo, em que o jogador interage simultaneamente com os conteúdos e a estrutura do jogo; com as representações que enunciam aqueles conteúdos e estrutura; com os dispositivos tecnológicos que os viabilizam e com os elementos de seu entorno material. (FRAGOSO, 2015, p. 214) 
Figura 4: três espaços na agência usuário-ambiente virtual

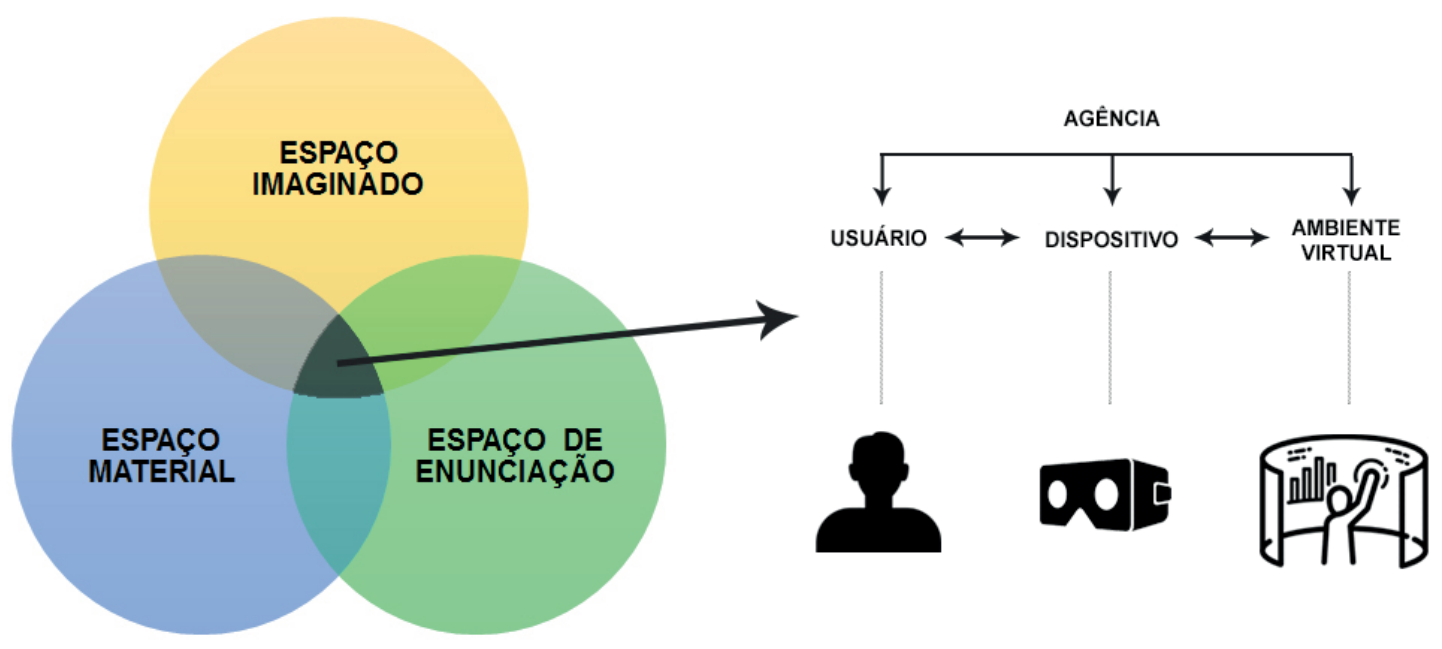

Fonte: adaptado de Fragoso (2015) e Zilles Borba (2016)

Problematizando a agência entre usuário e

ambiente virtual, Fragoso (2015) levanta três

tipos de espaço que emergem nessa relação:

espaço imaginado, espaço de enunciação e

espaço material (Figura 4). 0 espaço imaginado

é imaterial e diz respeito ao universo ficcional

do ambiente virtual, onde a narrativa ou os

acontecimentos se desenrolam. 0 espaço de

enunciação é a própria representação, um

espaço de mídias significantes: imagem, som e

texto. E o espaço material é físico, relacionado

com o corpo do usuário, os objetos do ambiente

e os equipamentos técnicos. Esses espaços

cruzam-se na agência entre jogador e jogo.

Assim, a experiência perceptiva do indivíduo é

complexa e dinâmica, sendo composta por limites

entrecruzados de três espaços.

\section{Metodologia}

Ao ter em conta que o objetivo deste artigo é

investigar as relações de materialidade, imaginário

e enunciação com a percepção espacial do sujeito

ao explorar cenários imersivos em RV através

do dispositivo HMD, considera-se imperativa a

aplicação de um estudo empírico que nos permita

verificar questões fenomenológicas da experiência,

no qual os dados acerca destas tecnointerações

sejam coletados a partir de práticas evidenciadas

na agência usuário-dispositivo-ambiente virtual.

A metodologia escolhida consistiu na realização

de experiências de exploração a ambientes de

RV por meio do Google Cardboard com oito

voluntários. Eles foram divididos em grupos 
de pessoas experientes e inexperientes no uso de dispositivos de RV ${ }^{12}$. Os interlocutores foram convidados pelo autor e seu assistente de pesquisa ${ }^{13}$, havendo apenas o cuidado em selecionar proporcionalmente os experientes e os inexperientes. Todos eram mestrandos ou doutorandos, com idade entre 25 e 39 anos. A escolha de estudantes de pós-graduação justifica-se tanto pela conveniência de contar com voluntários dispostos a participarem da pesquisa quanto pelo fato de traçarem um perfil de indivíduo que tem noções das dinâmicas de uso de interfaces computacionais (computador, celular, entre outros).

Cada voluntário utilizou um HMD em quatro cenários distintos: um passeio na montanha russa $^{14}$, uma viagem pelo espaço $0^{15}$, uma jornada pelo cérebro ${ }^{16}$ e uma visita ao apartamento ${ }^{17}$. A escolha desses cenários levou em consideração três aspectos: a) todos os ambientes virtuais eram de livre acesso, estando disponíveis para qualquer pessoa testar (incluindo o leitor deste artigo); b) todos os ambientes virtuais eram simples e fáceis de utilizar, bastando ao usuário seguir trajetos pré-definidos e/ou utilizar a técnica de look and go para se deslocar no cenário ${ }^{18}$; c) todos os ambientes virtuais geravam uma experiência espacial de envolvimento com paisagens tridimensionais, permitindo ao usuário perceber escalas, proporções, perspectivas e profundidades dos cenários em escalas reais, como se estivessem no seu entorno $\left(360^{\circ}\right)$.

Em seguida, individualmente, os usuários participaram de entrevistadas semiestruturadas, em que a atenção dos pesquisadores se mantinha flutuante, e caminhos contingentes da conversa foram bem-vindos. A entrevista abordou oito questões relacionadas à percepção de espaço (material, imaginado e de enunciação), à experiência de uso dos equipamentos e suas

Dois homens e duas mulheres experientes; e dois homens e duas mulheres inexperientes.

13 Esta etapa empírica do artigo contou com o auxílio de Samyr Paz, que é mestrando do Programa de Pós-Graduação em Indústria Criativa da Universidade Feevale, instituição na qual o autor atua como professor-convidado junto à disciplina de Mestrado intitulada Cognição e Percepção (em Realidade Virtual, Híbrida e Aumentada).

14 Dive City Coaster disponível em: https://itunes.apple.com/br/app/dive-city-rollercoaster/id771293168?mt=8. Acesso em 2 jan. 2017.

15 VR Space disponível em: https://itunes.apple.com/br/app/vr-roller-coaster-space-ship/id1119558686?mt=8. Acesso em 2 jan. 2017

16 InMind VR disponível em: https://itunes.apple.com/br/app/inmind-vr-cardboard/id971720127?mt=8. Acesso em 2 jan. 2017.

17 Dreamizer 3D VR disponível em: https://itunes.apple.com/br/app/dreamizer-3d-vr-for-cardboard/id957328891?mt=8. Acesso em 2 jan. 2017.

18 Look and go é uma técnica de navegação específica para HMDs, no qual o usuário direciona o seu olhar para os pontos que deseja se deslocar. Em ambientes virtuais mediados pelo monitor do computador esta técnica é realizada com o mouse e chama-se click and go (ZILLES BORBA, 2016). 
possíveis apropriações (affordances) e ao sentimento de imersão e presença no contexto virtual. Contudo, invariavelmente, os voluntários responderam a mais questões. E, a partir deste processo, foram confeccionados diários de campo com dados qualitativos ${ }^{19}$. A atividade foi realizada num dia, e cada participante ocupou uma hora, entre recepção, experiência de uso e entrevista.

0 dispositivo de RV utilizado pelos voluntários foi do tipo Cardboard. Ou seja, um equipamento do modelo HMD utilizado em conjunto com smartphones, neste caso, um iPhone 6 .

Esse dispositivo é menos sofisticado que 0 Oculus Rift, por exemplo. Entretanto, é mais acessível e móvel, pois não requer conexão a um computador com elevada capacidade de processamento gráfico. Por outro lado, o poder de processamento do smartphone resulta em gráficos computadorizados mais simples. Em suma, a escolha desse dispositivo é explicada pela sua acessibilidade se comparada com outros HMDs, especialmente devido ao baixo custo de aquisição do dispositivo (cerca de $\mathrm{R} \$ 10,00$ ) e à fácil integração com qualquer smartphone que possua tecnologia de giroscópio ${ }^{20}$.

Em geral, a experiência foi conduzida tanto pelo foco na observação - seguindo protocolos metodológicos etnográficos (ECKERT; ROCHA, 2008) - quanto pela interpretação das respostas na entrevista semiestruturada - com base nos estudos de imersão, presença, espacialidade e materialidade de Kerckhove (1995), Lévy (1996), Slater; Wilbur (1997), Sodré (2001), Burdea (2003), Gumbrecht (2004), Picon (2004), Luhman (2005), Ferreira (2007), Nagy; Neff (2005), Fragoso (2015), Zilles Borba (2016), entre outros.

\section{Análise e discussão dos dados}

A partir dos dados coletados com as entrevistas semiestruturadas e as observações exploratórias aos usuários, durante suas experiências em ambientes de RV com o dispositivo HMD, é apresentada uma discussão reflexiva acerca das percepções de espaço (material, imaginado e de enunciação), da sensação de imersão e das possíveis apropriações (affordances) na agência usuário-dispositivo-ambiente virtual. Esta análise é apresentada em dois tópicos referentes aos grupos de participantes inexperientes e experientes no uso de dispositivos de RV. Uma vez que se pretende compreender as percepções de espaço, de materialidade, de imersão e presença e, até mesmo, a influência do equipamento nessas experiências de mediação entre usuário e cenário virtual imersivo, parece-nos fundamental

19 Roteiro da entrevista e dados do diário de campo podem ser acessados neste link: https://www.dropbox.com/ s/tvk6i4l9ctaqpnt/anexos.pdf?dl=0

200 giroscópio é um dispositivo interno do celular que consegue detectar para onde o usuário está apontando 0 aparelho. Em sua essência, ele é um rotor suportado por dois círculos que funciona de acordo com os princípios da inércia. Isto é, sem precisar de coordenadas geográficas, 0 celular integrado com 0 HMD saberá indicar se 0 usuário está olhando para cima, para baixo ou para os lados em seis graus de liberdade (6-DOF). 
separar as análises nesses dois grupos. Afinal de contas, as experiências sociotécnicas dos mais experientes permite-lhes, a priori, ter uma associação mais habituada aos dispositivos.

\section{Inexperientes e o mergulho no contexto virtual}

0s voluntários inexperientes destacaram, em grande parte das experiências, aspectos técnicos do dispositivo. Porém, também ficou evidente que, apesar de não terem ciência, diversos aspectos narrativos (storytelling) e imaginários (psicológicos) dessas experiências os motivaram a mergulhar no contexto virtual (Tabela 1).

Todos os participantes sublinharam existir uma elevada sensação de presença no ambiente virtual, pois permitiam-se mergulhar no contexto da experiência. Isso significa que, mais do que valorizarem os estímulos sensoriais produzidos tecnicamente pelos equipamentos (transportarse sensorialmente para 0 espaço virtual), foi 0 envolvimento com 0 conteúdo do ambiente virtual que atraiu a sua atenção (mentalmente transportar-se para o espaço virtual). Ou seja, mais sensação de presença do que imersão (SLATER; WILBUR, 1997). Isso também nos faz refletir que, para este grupo de usuários, 0 envolvimento com os elementos do espaço de enunciação e do espaço imaginado foram mais responsáveis pela geração de uma noção de habitar o contexto virtual do que, propriamente, os elementos do espaço material.
Entretanto 0 espaço material não foi ignorado pelos participantes das explorações virtuais. De fato, para esta categoria de análise, foi diagnosticado que tanto o equipamento quanto o local físico em que as pessoas estavam produziram algum tipo de influência no processo de percepção das experiências. Por exemplo, por mais que os participantes 2, 3 e 4 tenham considerado o dispositivo HMD confortável de usar na cabeça e, por momentos, esquecessem o seu corpo no espaço físico para assumir uma espécie de simbiose de seus movimentos reais com os movimentos do corpo do avatar no cenário eletrônico (no espaço de enunciação), eles sempre diziam recordarem-se de que estavam sentados numa cadeira na sala de aula da universidade (no espaço material). Ou seja, apesar dos seus esforços em se concentrarem apenas no espaço da simulação, esses fatores físicos não eram totalmente ignorados. Isto é, sim, eles fazem parte da agência usuário-dispositivo-ambiente virtual e, consequentemente, da resolução interpretativa que a pessoa tem da experiência virtual (FRAGOSO, 2015).

As características de ação e interatividade da jornada no cérebro e da visita ao apartamento foram enfatizadas por todos os participantes inexperientes como as mais marcantes. Nelas, as interações foram avaliadas como mais participativas e, até mesmo, mais importante para a experiência do que a qualidade gráfica e estética vista nos demais cenários. 0s participantes 1, 2 e 4 indicaram que ambientes 
virtuais com maiores possibilidades de interações (e não somente experiências de visualização como o passeio na montanharussa ou a viagem pelo espaço) geravam uma espécie de simbiose entre usuário orgânico e personagem binário, numa extensão eletrônica dos seus movimentos e intenções (affordances). Neste caso, os usuários explicaram que, pelo fato de o HMD estar afixado em suas cabeças, e as interações se desprenderem pela técnica de look and go proporcionada pela técnica do giroscópio, eles sentiam uma fusão de sua cabeça com o HMD, como se ambos se tornassem um único elemento para ativar ações na paisagem eletrônica.

0 que nos parece mais interessante desses depoimentos é verificar que, apesar de assumirem a participação do Google Cardboard, a sua noção não era de terem que manusear mais um instrumento para explorar a simulação, mas, sim, de uma integração ferramenta e corpo. Contudo, também nos parece pertinente ressaltar que o participante 3 teve dificuldades em usar os comandos de navegação do HMD, o que prejudicou as suas interações e, certamente, anulou qualquer possibilidade de movimentos de apropriação do dispositivo por parte desse usuário. Em suma, isso nos faz pensar que, para os quatro interlocutores da pesquisa, a proatividade tanto do espaço material quanto do espaço de enunciação foi responsável por produzir experiências mais satisfatórias e envolventes.

Com exceção do participante 1, a percepção de espaço geral dos participantes era mais compreendida como lugares visitados do que apenas imagens visualizadas num ambiente virtual. Durante a sua entrevista, o participante 3 declarou que jamais teve coragem de andar numa montanha-russa. Porém, a RV permitiu que ele experimentasse algumas das sensações relacionadas a esta aventura. E, ao lembrar do que havia acabado de vivenciar, levou na sua memória o sentimento de uma experiência que realmente viveu em um lugar que realmente visitou, e não somente uma experiência de visualização de imagens tridimensionais num dispositivo de mídia. 
Tabela 1: síntese de dados sobre as explorações dos usuários inexperientes com dispositivos de RV

\begin{tabular}{|c|c|}
\hline $\begin{array}{c}\text { Usuários } \\
\text { Inexperientes }\end{array}$ & Relações e intersecções na agência usuário-dispositivo-ambiente virtual \\
\hline Participante 1 & $\begin{array}{l}\text { - Esperava visualizar cenários mais realísticos e com maior detalhamento gráfico. } \\
\text { - Em momento algum se desligou do corpo físico para mergulhar na experiência virtual. } \\
\text { - Relembra das experiências mais como imagens que viu do que lugares que visitou } \\
\text { - Preferiu as experiências em cenários mais realísticos (visual), considerando os demais "fakes". } \\
\text { - Valorizou as experiências que envolviam interatividade e tarefas a serem cumpridas. } \\
\text { - Considerou o equipamento confortável. } \\
\text { - Fez pouca movimentação na cadeira e com a cabeça. } \\
\text { - Sentia controle sobre o dispositivo. }\end{array}$ \\
\hline Participante 2 & $\begin{array}{l}\text { - As experiências proporcionaram uma união entre o corpo orgânico e o corpo do avatar (simbiose } \\
\text { usuário-personagem). } \\
\text { - Esperava sentir emoções maiores, como medo de altura ou náusea, o que não aconteceu. } \\
\text { - Relembra as experiências mais como lugares do que imagens visualizadas. } \\
\text { - Preferiu experiências com maior interatividade (mirar, atirar, etc.). } \\
\text { - Desvalorizou o realismo gráfico das experiências. } \\
\text { - Esqueceu que o dispositivo estava na sua cabeça. } \\
\text { - Considerou o equipamento confortável. } \\
\text { - Moveu-se apenas nas experiências que exigiam interatividade. } \\
\text { - Constantemente lembrava que estava sentado na cadeira da sala. }\end{array}$ \\
\hline Participante 3 & $\begin{array}{l}\text { - Estava receoso por utilizar o dispositivo de RV pela primeira vez, pois tinha visto vídeos de pessoas } \\
\text { fazendo "fiascos". } \\
\text { - } 0 \text { passeio na montanha russa permitiu fazer algo que nunca havia realizado no mundo físico. Entretanto } \\
\text { não sentiu medo da altura em momento algum. } \\
\text { - Relembra as experiências mais como lugares do que imagens visualizadas. } \\
\text { - Teve dificuldades em compreender os comandos de navegação na experiência do apartamento. } \\
\text { - Valorizou as experiências mais lúdicas e fantásticas (ex: jornada no cérebro; viagem espacial) e menos } \\
\text { realísticas (ex: apartamento). } \\
\text { - Movimentou-se pouco na cadeira e com a cabeça. } \\
\text { - } 0 \text { equipamento apertou um pouco o nariz, o que poderia gerar um desconforto maior caso a experiência } \\
\text { fosse mais longa. } \\
\text { - Lembrava que estava numa sala da universidade }\end{array}$ \\
\hline Participante 4 & $\begin{array}{l}\text { - Esqueceu-se parcialmente do seu corpo físico, pois fez tanto uso de referências visuais para ter } \\
\text { percepção do espaço como teve medo de bater com os braços nos móveis reais da sala. } \\
\text { - Relembra as experiências mais como lugares do que imagens visualizadas. } \\
\text { - As experiências com maior movimentações, tarefas e interatividade foram as que Ihe marcaram } \\
\text { (sensação de controle). } \\
\text { - Considerou o equipamento confortável. } \\
\text { - Moveu pouco o corpo. Apenas na visita ao apartamento ficou de pé e moveu-se } 360^{\circ} \text {. } \\
\text { - Sensação de calor do equipamento. }\end{array}$ \\
\hline
\end{tabular}




\section{Experientes e a técnica}

Sobre os voluntários experientes, é relevante apontar alguns detalhes antes de abordar os relatos de pesquisa. As duas mulheres participantes tinham menos experiência com dispositivos de RV do que os dois homens, pois eles atuam no setor de produção audiovisual e, consequentemente, já utilizaram inúmeras vezes os modelos de HMD. Em relação aos inexperientes, nota-se que este grupo tem um olhar mais crítico para as propriedades dos espaços de enunciação e material, especialmente para questões relacionadas a estética, qualidade gráfica, sonoridades (sensorialidade) e interatividade (equipamento). Neste sentido, podemos dizer que são pessoas que não atentaram a detalhes mentais e psicológicos das experiências, apesar de estarem presentes nas suas experiências (espaço imaginado). Também, é relevante destacar que, entre os usuários experientes, verificou-se uma tendência para resgatar memórias passadas, numa espécie de estímulo dos feelings de experiências passadas (reviver, relembrar, sentir novamente sensações) (Tabela 2).

Em oposição ao que foi diagnosticado entre os usuários inexperientes, tornou-se evidente que a familiaridade com os dispositivos de RV fez emergir um maior senso de atenção aos aspectos técnicos da experiência. Tanto em termos de hardware quanto de software, estes quatro voluntários demonstraram um poder de análise superior ao do grupo de inexperientes, estendendo as suas observações aos detalhes do espaço de enunciação como, por exemplo: campo de visão, design gráfico ou storytelling das experiências.

Durante as explorações aos ambientes de $\mathrm{RV}$, todos participantes do grupo experiente apontaram que o espaço material participa da experiência. 0s participantes 5 e 6, por exemplo, acharam 0 Google Cardboard pesado de vestir, mas também apontaram como positivo o fato de 0 equipamento bloquear qualquer elemento visual do mundo real. Por sua vez, os participantes $7 \mathrm{e}$ 8 sentiram-se confortáveis em vestir e manusear o HMD. Ainda, logo ao colocar o dispositivo, ambos os usuários verificaram que as bordas do telefone celular estavam aparecendo na integração como HMD, o que tornava a visualização do ambiente virtual menos realística, afinal sempre viam a estrutura do aparelho telefônico quando deveriam estar visualizando apenas imagens estereoscópicas em sua tela.

Todos os participantes valorizaram os momentos de maior interatividade com o conteúdo. A possibilidade de selecionar botões, menus ou caminhos específicos de navegação gerava uma certa liberdade de circulação no cenário virtual, a qual era bastante valorizada pelos participantes das experiências. Contudo, todos acharam que os quatro ambientes virtuais explorados tinham um baixo grau de exigência de interações. Isto é, apesar de haver uma grande liberdade para visualizar os ambientes em $360^{\circ}$, os movimentos de navegação eram limitados e 
tornavam a experiência menos imersiva. Notouse que o participante 7 tinha bastante domínio técnico para explorar os ambientes com os recursos do HMD. Isso foi diagnosticado devido aos seus comentários pertinentes sobre os modos de navegação durante as experiências e, principalmente, por se mover bastante na cadeira giratória. Por exemplo, virou diversas vezes 0 tronco e a cabeça para contemplar as paisagens virtuais, gesticulou com os braços e mão e, por vezes, levantou-se da cadeira para explorar 0 que havia ao seu redor. Em nossa visão, esse comportamento proporcionou que o participante 7 tivesse uma maior integração dos espaços materiais, imaginado e de enunciação em suas experiências, pois envolvia-se completamente com elementos dos três espaços.

Num sentido oposto, notamos que o participante 5 , apesar de alegar ter um total controle do dispositivo, mantinha-se, na maior parte do tempo, parado na cadeira, fazendo pouco uso da cabeça e/ou do torso para ver e interagir com os elementos virtuais. Provavelmente, os efeitos físicos de náuseas e tonturas que sentiu em algumas experiências justifiquem esse comportamento passivo na exploração dos conteúdos. Por exemplo, na interação com a montanha-russa, comentou: tive medo que minha cabeça fosse cair. Semelhante sensação de mal-estar foi relatada pelo participante 6 , ao se sentir angustiado, inquieto e apertado na visita ao apartamento. Inclusive, nessa situação, verificouse que 0 voluntário encolhia os braços e esquivava o seu corpo real (no mundo físico) dos objetos virtuais (no mundo digital).

Sobre a imersão e/ou sensação de presença, podemos dizer que nem todos os usuários experientes mergulharam sensorial ou mentalmente no contexto virtual. Os participantes 5 e 6 foram aqueles que se sentiram mais envolvidos no contexto virtual devido a uma combinação de estímulos sensoriais do dispositivo (imersão) e estímulos psicológicos devido à troca de atenção com 0 enredo (sensação de presença). 0 participante 6 , apesar de ter sido bastante crítico com a ausência de estímulos multissensoriais ${ }^{21}$, afirmou que, por vezes, esquecia-se do seu corpo no espaço físico. Isso ocorreu com maior intensidade na jornada ao cérebro, pois 0 enredo da experiência sugeria 0 cumprimento de objetivos e missões que prendiam a atenção do usuário no contexto virtual. De fato, isso nos faz refletir que o storytelling relacionado a estratégias de gamificação ajudam a criar um sentimento de presença na RV. Ou seja, por mais que a pessoa seja crítica e observadora dos 
elementos técnicos que atuam na construção da experiência sensorial (ver, ouvir, sentir, etc.), os elementos psicológicos incentivam o seu envolvimento com o contexto virtual ao ponto de atraírem uma elevada carga de atenção e, consequentemente, criarem uma noção de presença no cenário.

Por sua vez, os participantes 7 e 8 não tiveram essa sensação de mergulho no contexto virtual. Para o participante 7, por exemplo, a ausência de técnicas de embodiment (ver o seu corpo representado graficamente no cenário virtual) foi crucial para anular qualquer sentimento de imersão no espaço virtual. Ainda, o participante 8 sugeriu que a ausência de sonoridades naturais para os efeitos de áudio tornava as experiências menos realistas, pois tratava-se de sons sintéticos. Esse nível de percepção auditiva deve-se ao fato de este voluntário ser um profissional de áudio para jogos digitais. Ele também sugeriu que 0 uso de fones de ouvido poderia ajudar a criar experiências mais imersivas, pois eles ajudariam a anular os sons externos à cena virtual como, por exemplo: pessoas passando pelos corredores da universidade, portas batendo, conversas paralelas etc. Isto é, o fone de ouvido, ajudaria a anular ruídos do espaço material para dar maior ênfase às sonoridades do espaço de enunciação.

Por fim, os participantes 5, 6 e 7 foram aqueles que alegaram haver uma união do seu corpo com o dispositivo colocado na cabeça. Isso significa que, apesar de saberem que estavam utilizando uma ferramenta eletrônica, por momentos, existia uma simbiose entre utilizador e personagem, nomeadamente nos momentos de interatividade com os objetos da paisagem virtual. A experiência de jornada ao cérebro foi aquela que mais despertou essa relação de apropriação do Google Cardboard como uma extensão do corpo (affordances); afinal, era necessário exercer controle sobre a navegação no cenário e as interações com os objetos (mirar, atirar, caminhar, etc.).

Ao ser solicitado para pensar nas experiências realizadas com os quatro ambientes de $\mathrm{RV}, \mathrm{o}$ grupo de usuários experientes indicou variadas respostas. Dois participantes disseram se recordarem da experiência como uma visualização de imagens em dispositivos de mídias imersivas, enquanto um participante considera se lembrar da experiência como um lugar que visitou e, por fim, outro participante indica que as experiências com maior realismo gráfico ficaram em sua memória como um lugar que visitou (visita ao apartamento e montanha-russa), enquanto que aquelas com menos sofisticação gráfica são lembradas como imagens que viu numa tela em $360^{\circ}$ (viagem no espaço e jornada no cérebro).

Ainda, o participante 8 sublinhou que a experiência com a montanha-russa lhe trouxe memórias da infância, numa espécie de déjá $v u$ eletrônico (ZILLES BORBA; ZUFFO, 2018). Essas interpretações se devem ao fato de este grupo lançar um olhar mais crítico aos detalhes do espaço material e de enunciação dos 
ambientes de RV. Neste sentido, compreendeu-se que estes voluntários precisam de um impulso sensorial mais completo dos equipamentos (multissensorial) para que tenham uma sensação de imersão total no contexto (espaço material). Afinal dificilmente são enganados pelos estímulos artificiais gerados pelas máquinas informáticas, enquanto que, para alavancar a sensação de presença, é necessário que os cenários tenham maior interatividade (espaço de enunciação), pois os sujeitos já estão acostumados e familiarizados com as tecnointerações deste tipo de mídia e, especialmente, enredos narrativos capazes de atrair e manter a sua atenção focada nas missões, nos objetivos ou na trama do jogo/ambiente virtual (espaço imaginado).

Tabela 2: síntese de dados sobre as explorações dos usuários experientes com dispositivos de RV

\begin{tabular}{|c|c|}
\hline $\begin{array}{c}\text { Usuários } \\
\text { Experientes }\end{array}$ & Relações e intersecções na agência usuário-dispositivo-ambiente virtual \\
\hline Participante 5 & $\begin{array}{l}\text { - Relembra as experiências mais como imagens que viu do que lugares que visitou. Contudo a } \\
\text { experiência com a montanha-russa lhe despertou memórias passadas. } \\
\text { - Na montanha-russa e na viagem no espaço, sentiu náuseas e, por vezes, "tive medo que minha } \\
\text { cabeça fosse cair". } \\
\text { - Considerou haver pouca possibilidade de interação e navegação pelos cenários das quatro } \\
\text { simulações. } \\
\text { - Destacou a gamificação da jornada do cérebro como um incentivo a explorar o cenário. E, também, } \\
\text { o potencial comercial da experiência de visualização do apartamento. } \\
\text { - Considerou o equipamento pesado. } \\
\text { - Valorizou a capacidade do dispositivo em bloquear a visão e som advindo do espaço físico. } \\
\text { - Fez pouca movimentação na cadeira e com a cabeça. } \\
\text { - Sentia controle sobre o dispositivo. }\end{array}$ \\
\hline Participante 6 & $\begin{array}{l}\text { - Fez pouca movimentação na cadeira, mas, durante as explorações, tirava dúvidas com os } \\
\text { pesquisadores e relatava seus sentimentos. } \\
\text { - Considerou o equipamento pesado, porém confortável. } \\
\text { - Contudo, alegou que se esquecia do equipamento montado na sua cabeça. Mesmo que soubesse } \\
\text { que tinha uma tela afixada nos seus olhos (celular), considerou que o equipamento preenchia todo o } \\
\text { espaço material, criando um estímulo visual para se focar apenas no ambiente virtual. } \\
\text { - Valorizou o realismo da experiência sensorial com a montanha-russa. Contudo, apontou sentir } \\
\text { ausência do vento para simular outros fatores multissensoriais. } \\
\text { - Considerou mais importante os aspectos interativos do que os visuais. Assim, a jornada no cérebro } \\
\text { foi a que mais agradou, justamente, por existirem tarefas e missões - gamificação. } \\
\text { - Por momentos, esqueceu-se do seu corpo físico. Especialmente nas atividades em que fora exigido } \\
\text { um maior número de interações. } \\
\text { - Na visita ao apartamento sentiu-se angustiada e apertada no ambiente. Nesta experiência segurou- } \\
\text { se na cadeira real para sentir-se mais segura. } \\
\text { - Em três ambientes de RV sentiu ter controle do dispositivo (montanha-russa, viagem no espaço, } \\
\text { jornada no cérebro). } \\
\text { - Relembra as experiências mais como lugares que visitou do que imagens que visualizou, pois } \\
\text { cada um deles remetem a memórias pessoais (ex: andar na montanha-russa, montar maquetes dos } \\
\text { planetas na escola, etc.). }\end{array}$ \\
\hline
\end{tabular}




\begin{tabular}{|c|c|}
\hline Participante 7 & $\begin{array}{l}\text { - Utiliza dispositivos de RV com boa frequência (mensalmente). } \\
\text { - Moveu-se bastante na cadeira, girou o tronco e a cabeça para contemplar o ambiente. } \\
\text { - Gesticulou os braços e, por vezes, fez comentários sobre as cenas. } \\
\text { - Demonstrou domínio técnico para explorar o cenário } 360^{\circ} \text { e interagir com os objetos. } \\
\text { - Alegou que as bordas do celular estavam visíveis no dispositivo, o que tornava a visualização do } \\
\text { ambiente virtual menos realística. } \\
\text { - Sugeriu utilizar fones de ouvido para sentir-se mais imerso no cenário. } \\
\text { - As possibilidades de interatividade na jornada ao cérebro lhe agradaram. Contudo, foram as } \\
\text { experiências com maior realismo visual que Ihe marcaram (ex: visita ao apartamento). } \\
\text { - Na experiência de viagem ao espaço apontou existir uma música que não se encaixava com a } \\
\text { simulação de explorar os planetas. Isto comprova a sua atenção aos detalhes técnicos como, por } \\
\text { exemplo: gráficos, sonoridades (espaço de enunciação) e equipamento (espaço material). } \\
\text { - Reclamou que as simulações não utilizaram a técnica de virtual embodiment (ver seu corpo } \\
\text { representado no espaço virtual - braços, mãos, pernas ou pés). } \\
\text { - Nas experiências que seguiam uma rota automática considerou não exercer grande controle sobre } \\
\text { o dispositivo (montanha-russa e viagem ao espaço). } \\
\text { - Nas experiências que permitiam navegar livremente pelo cenário sentiu maior controle sobre o } \\
\text { dispositivo (jornada no cérebro e visita ao apartamento). } \\
\text { - Relembra as experiências visualmente mais realísticas como lugares que visitou (montanha-russa, } \\
\text { visita ao apartamento) e das mais fantásticas como imagens visualizadas (jornada no cérebro, } \\
\text { viagem ao espaço). }\end{array}$ \\
\hline Participante 8 & $\begin{array}{l}\text { - Utiliza dispositivos de RV com elevada frequência no trabalho (semanalmente). } \\
\text { - Moveu-se pouco na cadeira e visualizou parcialmente os ambientes } 360 . \\
\text { - Assim como o participante } 7 \text { demonstrou atenção aos detalhes técnicos, especialmente aos } \\
\text { aspectos gráficos e sonoros. } \\
\text { - Destacou que o equipamento utilizado nas explorações era menos sofisticado do que os que } \\
\text { utilizava no trabalho, o que resultou um menor realismo gráfico. } \\
\text { - Também destacou falta de qualidade de áudio nas experiências (hardware), o que segundo ele } \\
\text { poderia ser contornado com o uso de fones de ouvido. } \\
\text { - Por ser um profissional de áudio, o participante também sentiu falta de efeitos sonoros naturais. } \\
\text { Em sua percepção auditiva, as sonoridades eram extremamente sintéticas e, por isso, deixavam a } \\
\text { experiência mais artificial. } \\
\text { - Devido às características de interação a jornada ao cérebro foi considera a experiência mais } \\
\text { divertida e marcantes. } \\
\text { - Em momento algum desligou-se do seu corpo físico para assumir o corpo do personagem. } \\
\text { - Lembrava que estava sentado numa cadeira em uma sala da universidade. } \\
\text { - Valorizou as experiências que permitiam a liberdade de movimentação pelo ambiente virtual (ex: } \\
\text { visita ao apartamento). } \\
\text { - Por vários momentos esqueceu que o equipamento estava montado na sua cabeça. Porém, quando } \\
\text { visualizava as bordas do celular no dispositivo voltava a recordar sua existência. } \\
\text { - Considerou o equipamento confortável, mas um pouco pesado. } \\
\text { - Relembra os ambientes de RV mais como imagens visualizadas do que como lugares visitados. A } \\
\text { única exceção seria a montanha-russa, pois Ihe trouxe memórias de infância. }\end{array}$ \\
\hline
\end{tabular}

\section{Considerações finais}

Este trabalho desenvolveu uma abordagem

sociotécnica sobre os emergentes dispositivos

de realidade virtual, em específico os HMDs. Ao realizar um experimento de uso dos dispositivos

de RV com oito voluntários, sendo metade

inexperientes e outra metade de experientes,

questões como materialidade, percepção de

espaço e experiência de uso puderam ser 
analisadas com base nos dados coletados através de observações e entrevistas semiestruturadas sobre as práticas destes usuários.

0s usuários inexperientes focaram menos em questões técnicas, o que permite entender que sua percepção de espaço estava mais concentrada no espaço imaginado em relação ao espaço de enunciação. Como o som e a imagem eram gerados e apresentados (espaço de enunciação), as suas qualidades e o uso dos equipamentos (espaço material) pouco importavam, desde que a experiência proporcionasse a realização de seus desejos (espaço imaginado). Em oposição, para os usuários experientes 0 espaço de enunciação era 0 pilar de suas experiências e percepções espaciais.

Em geral, mesmo que nem todos os usuários percebessem, concluiu-se que a materialidade afetava a experiência e a percepção espacial em sua totalidade, sendo que para os usuários experientes a materialidade tinha uma conexão mais direta com 0 espaço de enunciação, enquanto os inexperientes relacionavam 0 espaço físico com o espaço ficcional. De qualquer forma, essas relações são constituintes da agência entre usuário e ambiente virtual pelos conceitos das affordances que conectam estímulos objetivos (sensorialidade) e subjetivos (troca de atenção), mas também a percepção de materialidade, as estéticas e a fusão do corpo orgânico do usuário tanto com o dispositivo (HMD) quanto com 0 cenário virtual (avatar).
0 trabalho agora se dirige para compreender outros pontos da relação uso e realidade virtual, que incluem questões como ideias dos projetistas, governança e modelos de negócios.

\section{Bibliografia}

BENJAMIN, Walter. A obra de arte na era de sua reprodutibilidade técnica. São Paulo: Abril, 1983. BURDEA, Grigore. Virtual Reality Technology. New York: Wiley \& Sons, 2003.

CASTELLS, Manuel. A Era da Informação: economia, sociedade e cultura. São Paulo: Paz e Terra, 1999.

DOMINGUES, Diana. Realidade virtual e a imersão em CAVEs. Revista Conexão - Comunicação e Cultura. Caxias do Sul, v. 3, n. 6, p.35-50, 2004.

ECKERT, Cornelia; ROCHA, Ana Luiza Carvalho da. Etnografia: saberes e práticas. In: Céli Regina Jardim Pinto e César Augusto Barcellos Guazzelli. (Org.).

Ciências Humanas: pesquisa e método. Porto Alegre: Editora da Universidade, 2008, p. 9-24. Série Graduação.

FERREIRA, Jairo. Midiatização: dispositivos, processos sociais e de comunicação. E- Compós, v.10, p.1-14, 2007.

FRAGOSO, Yara; FRAGOSO, Suely; FINKELSZTEIN, Alessandro.; BR00KS, Joseph; REBS, Rebeca. Systematic review versus internet search: considerations about availability and reliability of medical information regarding pregnancy in women with multiple sclerosis. Revista Brasileira de Epidemologia (Impresso), v. 15, p.896-903, 2012. FRAGOSO, Suely. A experiência espacial dos games e outros medias: notas a partir de um modelo teórico analítico das representações do espaço. Comunicação e Sociedade, Braga, v. 27, n.2, p. 213-229, 2015. GRAFT, Kris. (2014). The 5 trends that defined the 
game industry in 2014. [S.I.]: Gamasutra, 2015. Disponível em: < http://www.gamasutra.com/view/ news/232257/The_5_trends_that_defized_the_game_ industry_in_2014.php >. Acesso em: 17 Mar. 2017.

GUMBRECHT, Hans Ulrich. Production of Presence:

What Meaning Cannot Convey. Stanford: Stanford

University Press, 2004.

KERCKHOVE, Derrick. The Skin of Culture:

Investigating the new electronic reality. London: Kogan Page, 1995.

KIRNER, Cláudio; TORI, Romero. Introdução à Realidade Virtual, Realidade Misturada e Hiperrealidade. In: Kirner, C. \& Tori, R. (Org.). Realidade Virtual: conceitos, tecnologias e tendências. São Paulo: Editora Senac, p. 3-20, 2004.

LÉVY, Pierre. 0 que é virtual? São Paulo: 34, 1996.

LUHMANN, Nicklas. A Realidade dos Meios de

Comunicação. São Paulo: Paulus, 2005.

McLUHAN, Marshall. Understanding media: the extensions of man. New York: McGraw-Hill, 1964.

NAGY, Peter; NEFF, Gina. Imagined Affordance: Reconstructing a Keyword for Comunication Theory. Social Media + Society, v. 1, n. 9, 2015.

NEGROPONTE, Nicholas. Ser digital. Lisboa: Caminho, 1995.

PICON, Antoine. Architectural and the virtual. Towards a new materiality. In: Reeser, A. e Schafer, A. (Eds.).

Praxis - Journal of Writing + Building. Boston, 6 (1), p. 114- 121, 2004.

SLATER, Mel; WILBUR, Sylvia. A Framework for Immersive Virtual Environments (Five): Speculations on the Role of Presence in Virtual Environments.

Presence: Teleoperators and Virtual Environments.

Cambridge: MIT Press, v. 6, n. 6, s/n, 1997.

SODRÉ, Muniz. (2001). Tempo real e espaço

virtual exigem uma nova teoria da
Comunicação. [S.I.]. Disponível em: < http://www.uff. br/mestcii/muniz1.htm>. [Acesso: 19 Fev. 2017].

ZILLES BORBA, Eduardo; MESQUITA, Francisco; ZUFF0, Marcelo. Tecnologias e Dispositivos Imersivos: captação, integração, percepção e ação no contexto publicitário. Actas do $14^{\circ}$ Encontro Internacional de Arte e Tecnologia. Aveiro: Universidade de Aveiro, v. 1, p. 356-360, 2015.

ZILLES BORBA, Eduardo; CABRAL, Márcio; LOPES, Roseli; ZUFF0, Marcelo. VR Model to Explore Archaeological Sites in a Non-Destructive Way. $47^{\circ}$ Siggraph Proceedings - VR Village. Anaheim: ACM, 2016.

ZILLES BORBA, Eduardo; PAZ, Samyr.

Materialidades, Sociabilidades e Outras Possibilidades em Dispositivos de Realidade Virtual. Anais do XXXIX Congresso Brasileiro de Ciências da Comunicação - Intercom. São Paulo: Escola de Comunicações e Artes da Universidade de São Paulo - ECA-USP, v. 39, p.1-12, 2016.

ZILLES BORBA, Eduardo. Eu-Avatar: apontamentos sobre a simbiose utilizador-personagem ao explorar cenários eletrônicos com óculos de realidade virtual. Actas dos Dias da Investigação na UFP. Porto: Universidade Fernando Pessoa, v. 3, p.17-22, 2016 ZILLES BORBA, Eduardo; ZUFF0, Marcelo. Déjá-vu: revivendo experiências em ambientes de realidade virtual. Interin (UTP), Curitiba, v.23, n.1, p. 221237, 2018. 


\begin{tabular}{|c|c|}
\hline $\begin{array}{l}\text { Between Places and Images: } \\
\text { the use of virtual reality devices } \\
\text { and the spatial perception }\end{array}$ & $\begin{array}{l}\text { Entre Lugares e Imágenes: } \\
\text { el uso de dispositivos de realidad } \\
\text { virtual y la percepción espacial }\end{array}$ \\
\hline $\begin{array}{l}\text { Abstract } \\
\text { The work carries a sociotechnical approach to } \\
\text { investigate user relations with Virtual Reality } \\
\text { devices, specifically the Head-Mounted Display } \\
\text { (HMD). It is based on the principle that relations } \\
\text { and intersections of user-virtual environment agency } \\
\text { are governed by imagined, enunciation and material } \\
\text { spaces. An empirical experiment was conducted } \\
\text { with eight participants who explored immersive } \\
\text { scenarios with the HMD and, after the explorations, } \\
\text { a semi-structured interview was applied with them. } \\
\text { In short, it was possible to point out that perception } \\
\text { of imagined space was relevant to inexperienced } \\
\text { users, whereas enunciation space was relevant for } \\
\text { the experienced ones and, also, the material space } \\
\text { connected perceptions of space of both users. } \\
\text { Keywords } \\
\text { Virtual reality. Devices. Spatial perception. } \\
\text { Materiality. Communication technologies. }\end{array}$ & $\begin{array}{l}\text { Resumen } \\
\text { El trabajo presenta un enfoque sociotécnico } \\
\text { para investigar las relaciones de usuario con los } \\
\text { dispositivos de Realidad Virtual (RV), específicamente } \\
\text { el Head-Mounted Display (HMD). Se basa en el } \\
\text { principio de que las relaciones e intersecciones } \\
\text { de la agencia usuario-realidad virtual se rigen por } \\
\text { espacios imaginado, de enunciación y material. } \\
\text { Se realizó un experimento empírico, en que ocho } \\
\text { participantes exploraron ambientes inmersivos con } \\
\text { el HMD y, después, participaron en entrevistas semi- } \\
\text { estructuradas. En resumen, es posible señalar que } \\
\text { la percepción del espacio imaginado era relevante } \\
\text { para usuarios inexpertos, mientras que el espacio de } \\
\text { enunciación era relevante para los experimentados y, } \\
\text { además, el espacio material conectó las percepciones } \\
\text { de espacio de ambos usuarios. } \\
\text { Palabras-clave } \\
\text { Realidad virtual. Dispositivos. Percepción espacial. } \\
\text { Materialidad. Tecnologías de la comunicación. }\end{array}$ \\
\hline
\end{tabular}




\section{Expediente}

A revista E-Compós é a publicação científica em formato eletrônico da Associação Nacional dos Programas de Pós-Graduação em Comunicação (Compós). Lançada em 2004, tem como principal finalidade difundir a produção acadêmica de pesquisadores da área de Comunicação, inseridos em instituições do Brasil e do exterior.

\section{E-COMPÓS I www.e-compos.org.br I E-ISSN 1808-2599}

Revista da Associação Nacional dos Programas de Pós-Graduação em Comunicação.

Brasília, v.21, n.1, jan./abr. 2018.

A identificação das edições, a partir de 2008, passa a ser volume anual com três números.

Indexada por Latindex I www.latindex.unam.mx

\section{CONSELHO EDITORIAL}

Ada Cristina Machado Silveira, Universidade Federal de Santa Maria, Brasil Alda Cristina Silva da Costa, Universidade Federal do Pará, Brasil Alfredo Luiz Paes de Oliveira Suppia, Universidade Estadual de Campinas, Brasil Ana Regina Barros Rego Leal, Universidade Federal do Piauí, Brasil Ana Carolina Rocha Pessôa Temer, Universidade Federal de Goiás, Brasil André Luiz Martins Lemos, Universidade Federal da Bahia, Brasil Angela Cristina Salgueiro Marques, Universidade Federal de Minas Gerais, Brasil Ângela Freire Prysthon, Universidade Federal de Pernambuco, Brasil Antonio Carlos Hohlfeldt, Pontifícia Universidade Católica do Rio Grande do Sul, Brasil Arthur Ituassu, Pontifícia Universidade Católica do Rio de Janeiro, Brasil

Bruno Campanella, Universidade Federal Fluminense, Brasil

Cláudio Novaes Pinto Coelho, Faculdade Cásper Líbero, Brasil Cárlida Emerim, Universidade Federal de Santa Catarina, Brasil Carlos Eduardo Franciscato, Universidade Federal de Sergipe, Brasil Danilo Rothberg, Universidade Estadual Paulista, Brasil Denise Tavares da Silva, Universidade Federal Fluminense, Brasil Diógenes Lycarião, Universidade Federal do Ceará, Brasil Eduardo Vicente, Universidade de São Paulo, Brasil Eliza Bachega Casadei, Escola Superior de Propaganda e Marketing - SP, Brasil Eneus Trindade, Universidade de São Paulo, Brasil

Erick Felinto de Oliveira, Universidade do Estado do Rio de Janeiro, Brasil Erly Vieira Júnior, Universidade Federal do Espírito Santo, Brasil Francisco de Assis, FIAM-FAAM Centro Universitário, Brasi

Francisco Elinaldo Teixeira, Universidade Estadual de Campinas, Brasil Francisco Gilson R. Pôrto Jr., Universidade Federal do Tocantins, Brasil Frederico de Mello Brandão Tavares, Universidade Federal de Ouro Preto, Brasil Gabriela Reinaldo, Universidade Federal do Ceará, Brasil Gilson Vieira Monteiro, Universidade Federal do Amazonas, Brasil Gustavo Daudt Fischer, Universidade do Vale do Rio dos Sinos, Brasil Itania Maria Mota Gomes, Universidade Federal da Bahia, Brasil Jiani Adriana Bonin, Universidade do Vale do Rio dos Sinos, Brasil José Afonso da Silva Junior, Universidade Federal de Pernambuco, Brasil José Luiz Aidar Prado, Pontifícia Universidade Católica de São Paulo, Brasil Josette Maria Monzani, Universidade Federal de São Carlos, Brasi Juçara Gorski Brittes, Universidade Federal de Ouro Preto, Brasil
Juliana Freire Gutmann, Universidade Federal da Bahia, Brasil Laura Loguercio Cánepa, Universidade Anhembi Morumbi, Brasil Leonel Azevedo de Aguiar, Pontifícia Universidade Católica do Rio de Janeiro, Brasil Letícia Cantarela Matheus, Universidade do Estado do Rio de Janeiro, Brasil Luciana Coutinho Souza, Universidade de Sorocaba, Brasil Maria Ataide Malcher, Universidade Federal do Pará, Brasil Maria Elisabete Antonioli, Escola Superior de Propaganda e Marketing - SP, Brasil Maria das Graças Pinto Coelho, Universidade Federal do Rio Grande do Norte, Brasil Marialva Carlos Barbosa, Universidade Federal do Rio de Janeiro, Brasil Marcel Vieira Barreto Silva, Universidade Federal da Paraíba, Brasil Marcia Tondato, Escola Superior de Propaganda e Marketing, Brasil Marli Santos, Universidade Metodista de São Paulo, Brasil

Márcio Souza Gonçalves, Universidade do Estado do Rio de Janeiro, Brasil Mauricio Mario Monteiro, Universidade Anhembi Morumbi, Brasil Mayka Castellano, Universidade Federal Fluminense, Brasil

Mozahir Salomão Bruck, Pontifícia Universidade Católica de Minas Gerais, Brasil Nísia Martins Rosario, Universidade Federal do Rio Grande do Sul, Brasil Paolo Demuru, Universidade Paulista, Brasil

Paula Melani Rocha, Universidade Estadual de Ponta Grossa, Brasil Potiguara Mendes Silveira Jr, Universidade Federal de Juiz de Fora, Brasil Priscila Ferreira Perazzo, Universidade Municipal de São Caetano do Sul, Brasil Rafael Cardoso Sampaio, Universidade Federal do Paraná, Brasil Rafael Tassi Teixeira, Universidade Tuiuti do Paraná, Brasil Regiane Lucas Garcês, Universidade Federal de Minas Gerais, Brasil Regiane Regina Ribeiro, Universidade Federal do Paraná, Brasil Renata Pitombo Cidreira, Universidade Federal do Recôncavo da Bahia, Brasil Renato Essenfelder, Escola Superior de Propaganda e Marketing, Brasil Roberto Elísio dos Santos, Universidade Municipal de São Caetano do Sul, Brasil Rodolfo Rorato Londero, Universidade Estadual de Londrina, Brasil Roseli Figaro, Universidade de São Paulo, Brasil

Simone Maria Andrade Pereira de Sá, Universidade Federal Fluminense, Brasil Sofia Cavalcanti Zanforlin, Universidade Católica de Brasília, Brasil Sônia Caldas Pessoa, Universidade Federal de Minas Gerais, Brasil Tatiana Oliveira Siciliano, Pontifícia Universidade Católica do Rio de Janeiro, Brasil Thaïs de Mendonça Jorge, Universidade de Brasília, Brasil

Valquiria Michela John, Universidade Federal do Paraná, Brasil

\section{CONSELHO CIENTÍFICO}

Cristiane Freitas Gutfreind, Pontifícia Universidade Católica do Rio Grande do Sul, Brasil I Eduardo Antônio de Jesus, Universidade Federal de Minhas Gerais, Brasil | Eduardo Morettin, Universidade de São Paulo, Brasil I Irene de Araújo Machado, Universidade de São Paulo, Brasil I Miriam de Souza Rossini, Universidade Federal do Rio Grande do Sul, Brasil

\section{COMISSÃO EDITORIAL}

Igor Pinto Sacramento, Universidade Federal do Rio de Janeiro, Brasil I Kelly Cristina de Souza Prudencio, Universidade Federal do Paraná, Brasil I Osmar Gonçalves dos Reis Filho, Universidade Federal do Ceará, Brasil I Rafael Grohmann, Faculdade Cásper Líbero, Brasil I Thaiane Moreira de Oliveira, Universidade Federal Fluminense, Brasil (editores associados)

\section{CONSULTORES AD HOC}

Afonso de Albuquerque, Universidade Federal Fluminense, Brasil I Cláudia Lago, Universidade de São Paulo, Brasil I Cesar Baio Santos, Universidade Federal do Ceará, Brasil I Eduardo Pellanda, Pontifícia Universidade Católica do Rio Grande do Sul, Bras | Francisco Rüdiger, Pontifícia Universidade Católica do Rio Grande do Sul, Brasil | Karina Woitowicz, Universidade Estadual de Ponta Grossa, Brasil I Luis Mauro Sa Martino, Faculdade Cásper Líbero, Brasil I Norval Baitello Jr, Pontifícia Universidade Católica de São Paulo, Brasil I Pedro Guimarães, Universidade de Campinas, Brasil

\section{EQUIPE TÉCNICA}

ASSISTENTES EDITORIAIS Márcio Zanetti Negrini e Melina Santos | REVISÃO DE TEXTOS Fátima Áli I EDITORAÇÃO ELETRÔNICA Roka Estúdio

COMPÓS I www.compos.org.br

Associação Nacional dos Programas de Pós-Graduação em Comunicação

Presidente

Marco Roxo

Programa de Pós-Graduação em Comunicação - UFF

marcos-roxo@uol.com.br

Vice-Presidente

Isaltina Gomes

Programa de Pós-Graduação em Comunicação - UFPE

isaltina@gmail.com

Secretária-Geral

Gisela Castro

Programa de Pós-Graduação em Comunicação

e Práticas de Consumo - ESPM

castro.gisela@gmail.com

CONTATO I revistaecompos@gmail.com 